Intecoms: Journal of Information Technology and Computer Science

Volume 1 Nomor 1, Juni 2018

e-ISSN : 2614-1574

p-ISSN : 2621-3249

DOI : https://doi.org/10.31539/intecoms.v1i1.161

\title{
TEKNIK MARKER BASED TRACKING AUGMENTED REALITY UNTUK VISUALISASI ANATOMI ORGAN TUBUH MANUSIA BERBASIS ANDROID
}

\section{MARKER BASED TRACKING AUGMENTED REALITY TECHNIQUE FOR THE VISUALIZATION OF HUMAN ORGANS ANATOMY BASED ON ANDROID}

\author{
Ika Devi Perwitasari \\ Universitas Pembangunan Panca Budi Medan \\ ikadeviperwitasari@dosen.pancabudi.ac.id
}

\begin{abstract}
This study aims to learn the technique of Marker Based Tracking Augmented Reality which is implemented for Visualization of Anatomy of Human Body Organs. Augmented Reality Visualization Applications Anatomy of the Human Body Organ is built on the Android mobile platform device. In the analysis of the application interface design using the approach of User Center Design (UCD). Testing the application using Usability Test. Based on the results of implementation and testing, Marker Based AR technique successfully applied in making Visualization Applications Anatomy Human Body Organson Android Platform. Applications use markers to display digital content (2D images of the brain, eyes, heart, and lungs). The results of the Usability Test show users can see organ anatomy information very clearly and users are very interested in using the applications created because it provides a different experience in learning.
\end{abstract}

Keywords : Augmented Reality, Marker Based Tracking, Human Organs, User Center Design

\begin{abstract}
ABSTRAK
Penelitian ini bertujuan untuk mempelajari teknik Marker Based Tracking Augmented Reality yang diimplementasikan untuk Visualisasi Anatomi Organ Tubuh Manusia. Aplikasi Augmented Reality Visualisasi Anatomi Organ Tubuh Manusia dibangun pada perangkat mobile platform Android. Dalam analisis perancangan antarmuka aplikasi menggunakan pendekatan User Center Design (UCD). Pengujian aplikasi menggunakan UsabilityTest. Berdasarkan hasil implementasi dan pengujian, teknik Marker Based AR berhasil diterapkan dalam pembuatan Aplikasi Visualisasi Anatomi Organ Tubuh Manusia Pada Platform Android. Aplikasi menggunakan marker untuk menampilkan konten digital (image $2 D$ otak, mata, jantung, dan paru-paru). Hasil dari Usability Test menunjukkan pengguna dapat melihat informasi anatomi organ dengan sangat jelas dan pengguna sangat tertarik menggunakan aplikasi yang dibuat karena memberikan pengalaman yang berbeda dalam belajar.
\end{abstract}

Kata Kunci :Augmented Reality, Marker Based Tracking, Organ tubuh Manusia, User Center Design

\section{PENDAHULUAN}

Dalam perkembangan teknologi pengolahan image saat ini telah melahirkan berbagai teknologi baru, salah satunya Augmented Reality (AR). Augmented Reality dapat didefinisikan sebagai penggabungan objek atau komponen digital dengan objek-objek nyata yang akan ditampilkan dengan interaktif dan real time (Azuma R. T., 1997).

Berdasarkan beberapa penelitian sebelumnya, AR telah dimanfaatkan di beberapa bidang yaitu bidang arsitektur dan desain interior, bidang medis serta bidang bisnis. Dalam bidang pendidikan AR juga mulai diimplementasikan. 
Melihat potensi teknologi Augmented Reality yang telah dipaparkan, selanjutnya penulis melakukan penelitian pengembangan media belajar dengan menerapkan teknik Augmented Reality untuk memvisualisasi anatomi organ tubuh manusia. Dengan menggunakan media pembelajaran yang menerapkan AR diharapkan seseorang akan mendapat pengalaman belajar yang berbeda.

\section{Augmented Reality}

Reality-Virtuality Continuum meliputi ruang antara realitas (reality) di mana segala sesuatu ada dalam bentuk fisik (physical environment), dan virtual reality di mana lingkungan ataupun objek virtual dan sintesa komputer grafik menggantikan lingkungan fisik. Mixed reality (realitas yang bercampur) berada diantaranya yang meliputi Augmented Reality dan Augmented Virtuality (Milgram and Kishino, 1994).

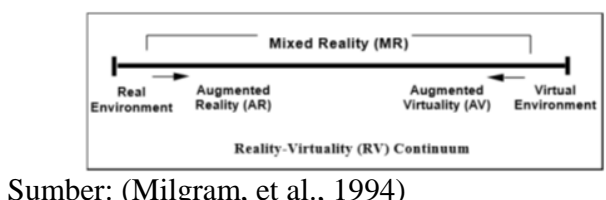

Gambar 1. Representasi Reality - Virtual (VR) Continuum

Augmented Reality menambahkan virtual konten ke dalam lingkungan nyata (real environment), sedangkan Augmented Virtuality menambahkan konten nyata (real content) ke dalam lingkungan virtual yang lebih dominan (Olwal A., 2009).

Teknologi Augmented Reality adalah sebuah teknologi visual yang menggabungkan objek atau dunia virtual ke dalam tampilan dunia nyata secara real time (Rekimoto J. and Ayatsuka Y., 2000).
Augmented Reality (AR) mengacu pada situasi di mana tujuannya adalah untuk melengkapi persepsi pengguna dari dunia nyata melalui penambahan objek maya (Azuma R. T., 1997).

Ada beberapa tipe tracking yang dapat digunakan dalam Augmented Reality yaitu (Raj K., A. D'Souza, A., Shanbhag, C., and D'Shouza, D., 2015):

Marker based tracking: marker based tracking adalah metode AR yang menggunakan marker atau penanda untuk memunculkan objek maya.

Markerless : dengan menggunakan metode markerless pengguna tidak memerlukan sebuah marker untuk menampilkan objek maya. Metode markerless dapat diterapkan dengan menggunakan GPS, motion (gestur), face tracking.

Dalam penelitian ini nantinya, untuk memvisualisasikan anatomi organ tubuh manusia akan menggunakan teknik AR Marker Based Tracking.

\section{UCD (User Center Design)}

User Center Design (UCD) merupakan pendekatan untuk membangun sistem yang interaktif dimana fokus utamanya adalah membuat sistem atau aplikasi yang mudah untuk digunakan (ISO/IEC, 1999).

Dengan mengadopsi pendekatan UCD dalam merancang antarmuka sistem, hasil akhir sistem diharapkan dapat memenuhi hal-hal berikut:

Membantu user dalam mencapai tujuannya, membuat orang ingin menggunakan sistem tersebut. Pengguna mudah mengerti bagaimana cara menggunakan sistem, sistem sukses digunakan oleh pengguna, memuaskan bagi pengguna, mengurangi kemungkinan kesalahan dari pengguna. 


\section{Vuforia SDK}

Vuforia merupakan Augmented Reality Software Development Kit (SDK). Vuforia SDK memungkinkan pengembangan Augmented Reality pada perangkat mobile. Vuforia dulunya juga dikenal dengan QCAR (Qualcomm Company Augmented Reality). Vuforia menggunakan teknologi Computer Vision untuk mengenali dan melacak gambar planar (Target Image). Kelebihan dari kemampuan pengolahan Qualcomm Augmented Reality yaitu :

Teknologi Computer Vision digunakan untuk menyeimbangkan gambar yang tercetak dan objek 3D. Mendukung beberapa tools development (Eclipse, Android, Xcode).

Vuforia menyediakan Application Programming Interface (API) di $\mathrm{C}++$, Objective-C, Java. Vuforia SDK mendukung pembangunan aplikasi untuk platform Android dan iOS. Gambar 2 Menjelaskan bagaimana proses pembangunan aplikasi menggunakan Vuforia.

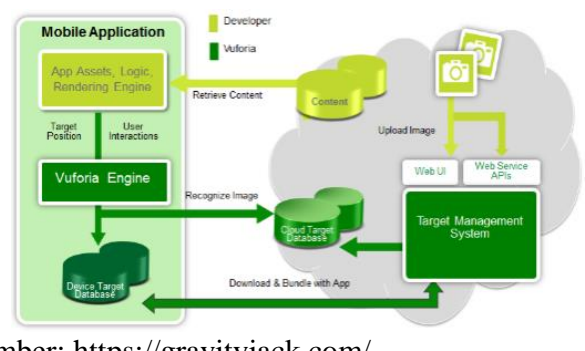

Sumber: https://gravityjack.com/

Gambar 2. Proses Registrasi Target

\section{Usability}

Sebuah sistem agar dapat diterima (acceptability) pengguna harus memiliki nilai, sistem harus cukup baik dan memenuhi kebutuhan penggunanya. Secara praktis acceptability dapat dideskripsikan melalui biaya yang terjangkau, compatible dengan sistem yang sudah ada, realiability, dukungan yang diberikan dan kegunaan / manfaatnya. Kegunaan sistem dapat dipecah lagi menjadi utility dan usability. Utility merupakan value untuk mengukur fungsional sistem seperti apa yang sistem bisa lakukan. Sedangkan usability merupakan value seberapa baik sistem tersebut dapat digunakan termasuk di dalamnya semua aspek dari sistem di mana manusia bisa melakukan interaksi (interface). Usability memiliki lima atribut yaitu (Nielsen J., 2000):

Learnability (mudah dipelajari), efficiency, Memorability (mudah diingat), errors (identifikasi error dalam usability test) dan satisfaction (kepuasan).

Dengan mendefinisikan kelima komponen tersebut, usability dapat dievaluasi secara sistematis untuk kemudian dilakukan perbaikan pada sistem.

\section{Unity 3D}

Unity (lebih dikenal dengan Unity3D) adalah sebuah game engine dan Integrated Development Environtment (IDE) untuk membuat media interactive, video games. CEO Unity David Helgason menyatakan bahwa Unity adalah sebuah Toolset yang digunakan untuk membangun game, teknologi Unity mengeksekusi grafik, audio, fisik, interaksi dan jaringan. Versi pertama dari Unity dibuat oleh David Helgason, Joachim Ante dan Nicholas Francis di Denmark (Brodkin, 2013).

\section{METODE PENELITIAN \\ Kerangka Penelitian \\ Studi Literature}

Hal yang dilakukan pertama kali adalah studi literatur, peneliti membaca artikel-artikel dan hasil penelitian yang dilakukan orang lain. Studi literatur dilakukan dengan membaca buku, proceeding, jurnal-jurnal dan paper. 


\section{Menyusun Proposal Penelitian}

Dalam rangka menyusun proposal penelitian, terlebih dahulu mengidentifikasi masalah kemudian merumuskannya dalam bentuk kalimat tanya, setelah rumusan masalah dibuat langkah selanjutnya yaitu merumuskan tujuan, kemudian menentukan metodologi yang akan digunakan.

Dalam penelitian ini hasil akhirnya adalah membangun aplikasi untuk visualisasi anatomi organ tubuh manusia menggunakan teknik Marker Based AR berbasis Android. Sedangkan metode yang digunakan adalah teknik Marker Based Tracking Augmented Reality, untuk rancangan antarmuka menggunakan pendekatan UCD (User Center Design).

\section{Analisa Kebutuhan}

Pada tahap analisis kebutuhan akan diidentifikasi kebutuhan dari sistem/perangkat lunak yang akan dibangun, mulai dari software dan hardware yang diperlukan, data dan kebutuhan fungsional dari perangkat lunak.

\section{Merancang Sistem}

Tahap merancang sistem mencakup semua tahap perancangan, yaitu perancangan antarmuka, pemodelan sistem dengan UML, menentukan konten digital dan marker.

\section{Konstruksi (coding)}

Proses coding dilakukan setelah rancangan sistem diselesaikan. Aplikasi yang akan dibangun berbasis Android sehingga pemrograman yang digunakan adalah pemrograman berbasis mobile. Dalam tahap kontruksi ini menggunakan IDE Unity 3D, Library Vuforia SDK dan C\#.

\section{Implementasi dan Pengujian}

Tahap implementasi dan pengujian merupakan tahap akhir. Setelah proses coding selesai, aplikasi dibuat dalam bentuk ekstensi .apk kemudian diinstal pada smartphone dengan platform Android. Selanjutnya dilakukan pengujian untuk mengukur usability perangkat lunak.

\section{Teknik Visualisasi}

Untuk menampilkan objek pada screen smartphone, dilakukan pembacaan marker oleh kamera. Marker yang teregistrasi dalam aplikasi akan menampilkan objek dan informasi tertentu pada screen smartphone. Mekanisme visualisasi menggunakan teknik Marker Based AR dapat dilihat pada Gambar 3.

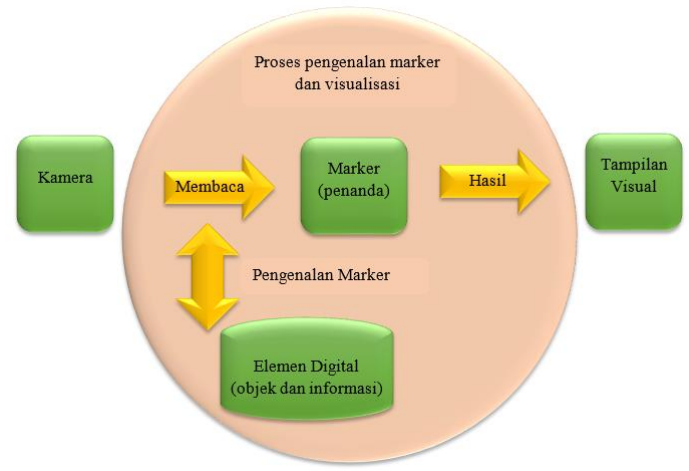

\section{Gambar 3. Kerangka Teknik Pengenalan} Marker

\section{Kamera}

Kamera dalam AR berfungsi sebagai alat pembaca marker sekaligus perekam keadaan lingkungan objek berada. Lingkungan dan objek yang terekam dikamera nantinya akan ditampilkan pada layar (dalam hal ini screen smartphone).

\section{Marker}

Marker atau penanda memiliki ciri khusus untuk menampilkan objek sesuai dengan yang terdaftar pada marker tersebut. Marker akan dikenali melalui kamera kemudian menampilkan 
elemen real dan objek virtual sekaligus di dalamnya ke dalam layar smartphone.

\section{Elemen Digital}

Elemen digital berupa image dan informasi akan muncul pada layar ketika marker dikenali. Dalam hal ini elemen digital yang disimpan adalah bentuk 2D organ-organ tubuh manusia beserta informasi atau keterangan bagian-bagian dari anatomi organ tersebut.

Elemen digital yang terkandung dalam aplikasi antara lain anatomi otak (brain anatomy), anatomi jantung (heart anatomy), anatomi paru-paru, dan anatomi mata (eye anatomy).

\section{Kebutuhan Sistem}

Software dan hardware yang digunakan peneliti untuk membangun aplikasi visualisasi anatomi organ tubuh manusia dengan teknik Marker Based AR antara lain:

Software yang terdiri dari sistem operasi Windows Pro 10, unity 3D, JDK (Java Development Kit), vuforia SDK dan adobe photoshop CS3.

Hardware yang terdiri dari laptop ASUS X455L series, kapasitas chip processing 1,9 GHz, dan RAM 2 GB

Aplikasi yang dibangun berbasis mobile, dibutuhkan perangkat smartphone untuk mengimplementasikan aplikasi yang dibuat. Berikut piranti yang dibutuhkan: Smartphone dengan platform Android 4.1 (Jelly Bean), kamera 8 MP dan Screen (layar) 4 inch

\section{HASIL DAN PEMBAHASAN Perancangan Alur Sistem}

Alur perencanaan aplikasi Augmented Reality visualisasi anatomi organ tubuh manusia yang akan dibangun dapat dilihat pada Gambar 4 dengan penjelasannya sebagai berikut.

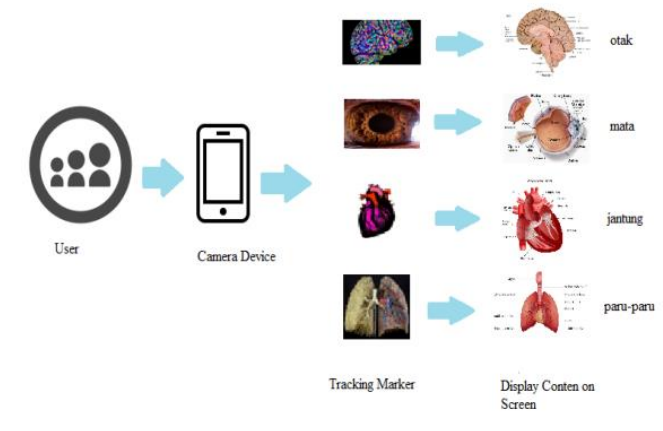

Gambar 4. Augmented Reality System Visualized Human Organ Anatomy

1. Aplikasi dibangun untuk perangkat mobileplatform Android.

2. Ketika user memilih ikon aplikasi maka aplikasi akan dijalankan dan menampilkan halaman menu utama

3. Pada halaman menu utama terdapat tiga menu yaitu AR Organ, AR Fungsi dan Panduan

4. Saat user memilih menu AR Organ atau AR Fungsi aplikasi akan mengaktifkan fitur kamera.

5. Fitur kamera diaktifkan untuk melakukan trackingmarker.

6. Untuk tracking marker melalui kamera, user harus menempatkan marker didepan kamera agar kamera dapat menangkap dan membaca marker.

7. Jika marker dikenali, layar kemudian akan menampilkan objek sesuai dengan yang terdaftar pada marker tersebut.

\section{Tahapan Konstruksi Program (Coding)}

Pembuatan aplikasi Augmented Reality Visualisasi Anatomi Organ Tubuh Manusia Berbasis Android menggunakan Unity 3D dan Vuforia SDK. Aplikasi AR yang dibuat menggunakan marker, adapun tahapan dalam proses konstruksi program dapat dilihat pada Gambar 5. 


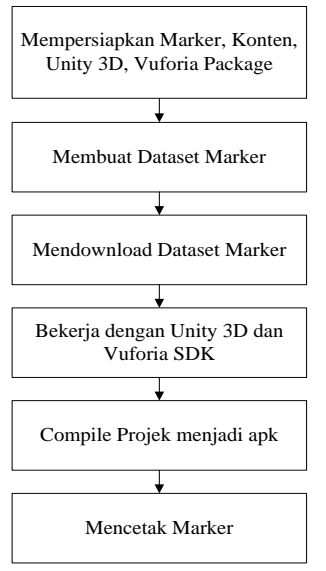

Gambar 5. Bagan Proses Konstruksi Program

Marker atau penanda yang digunakan adalah gambar yang didapat dari internet dan sumbernya telah disebutkan. Berikut marker yang akan digunakan dalam aplikasi.

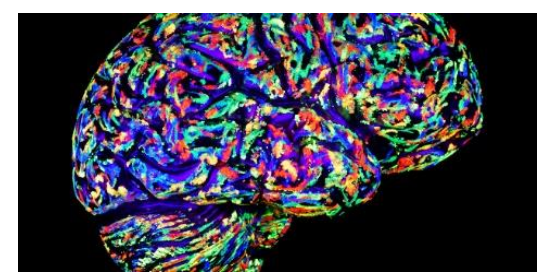

Sumber: http://i.huffpost.com/gen/

Gambar 6. Marker Organ Otak

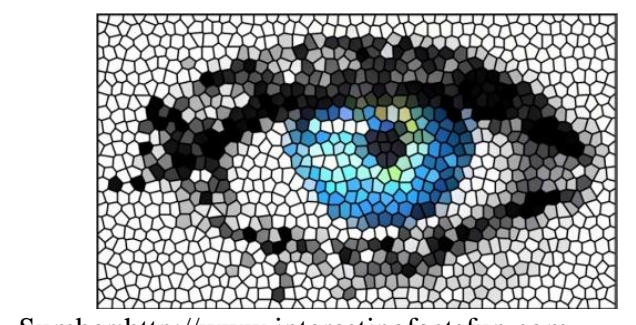

Sumber:http://www.interestingfactsfun.com

Gambar 7. Marker Organ Mata

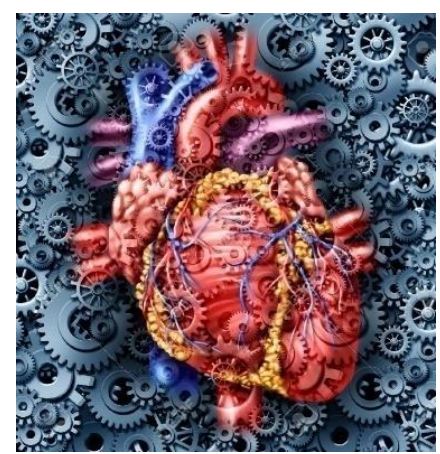

Sumber: http://previews.123rf.com

Gambar 8. Marker Organ Jantung

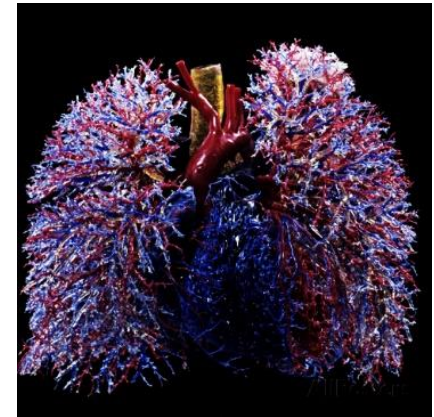

Sumber: http://imgc.allpostersimages.com

Gambar 9. Marker Organ Paru-Paru

\section{Tampilan Program}

Aplikasi visualisasi anatomi organ tubuh manusia dengan marker based augmented reality ini dinamakan HOVAR (Human Organ Anatomy Visualized with Augmented Reality). Untuk proses instalasi projek yang telah dijadikan apk dipindahkan ke smartphone.

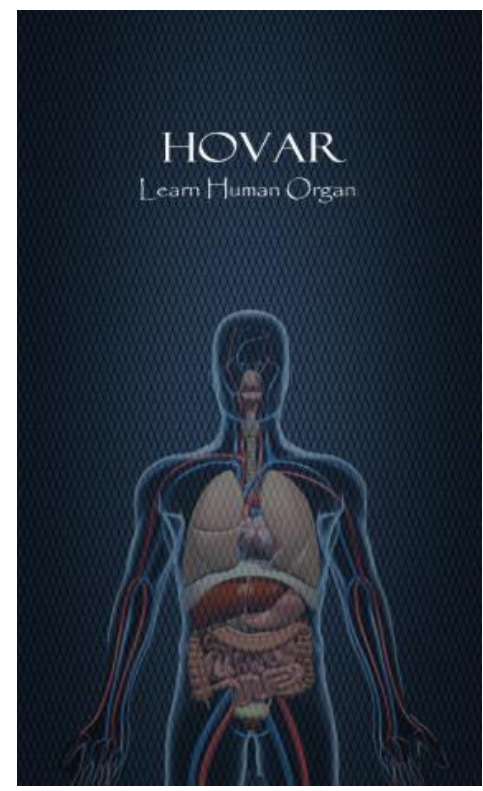

Gambar 10. Splash Screen

Tampilan splash screen akan diikuti dengan tampilan loading page. menu pada aplikasi akan terlihat setelah aplikasi selesai di-load. 


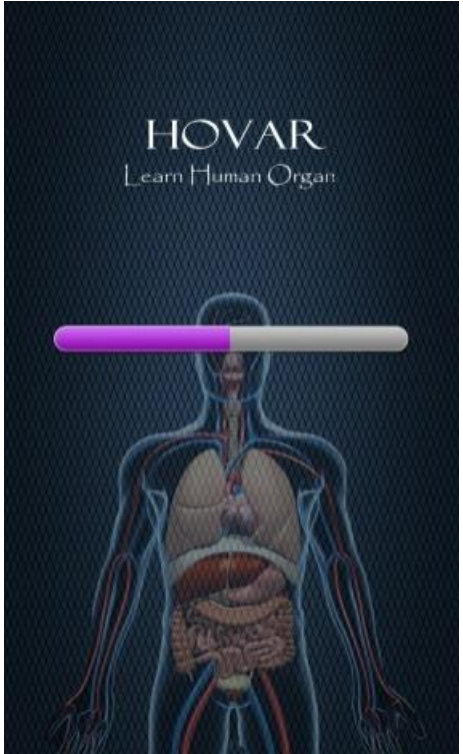

Gambar 11. Loading Page

Gambar 11 merupakan tampilan menu utama apliksi HOVAR. Pada menu utama ini terdapat tiga menu yaitu AR Organ, AR Fungsi dan Panduan.

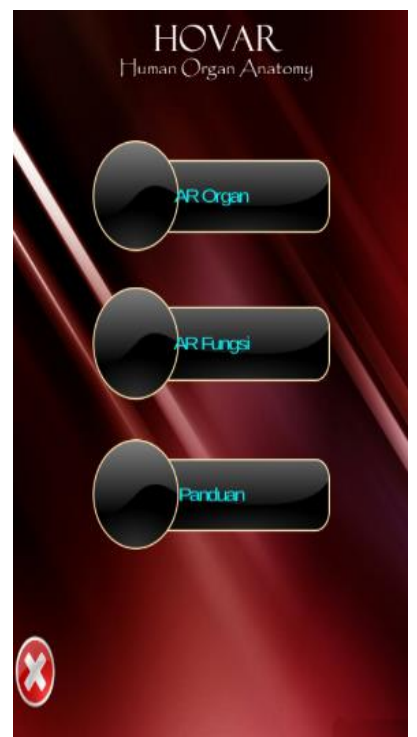

Gambar 12. Menu Utama Aplikasi HOVAR

Menu panduan akan menampilkan panduan menggunakan aplikasi augmented reality visualisasi anatomi organ tubuh. Pada halaman panduan ini pengguna juga diberikan informasi email penulis agar bisa mengirimkan pertanyaan atau saran.

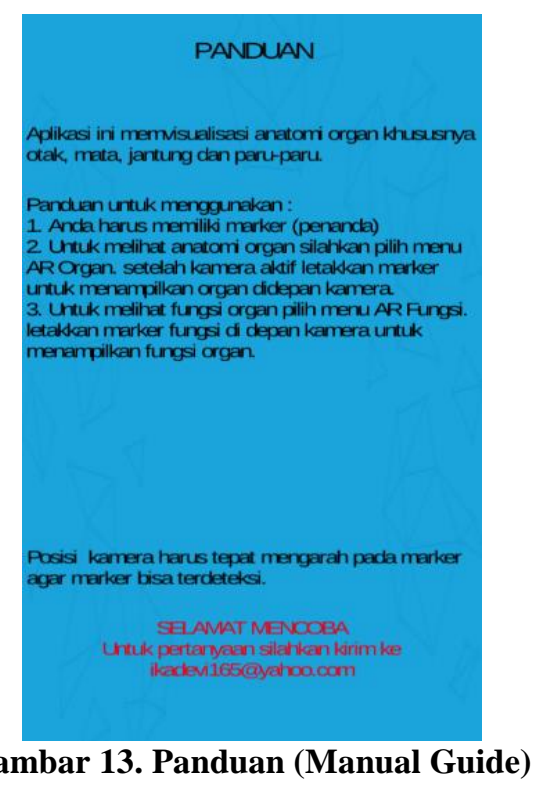

Menu AR Organ digunakan untuk menampilkan anatomi organ tubuh dalam bentuk gambar. Saat menu AR Organ di-klik fitur kamera akan diaktifkan. User dapat memilih marker dan meletakkan marker pada jangkauan kamera. Kamera akan mencoba mengenali pola marker, kemudian jika marker dikenali maka konten anatomi organ akan ditampilkan.

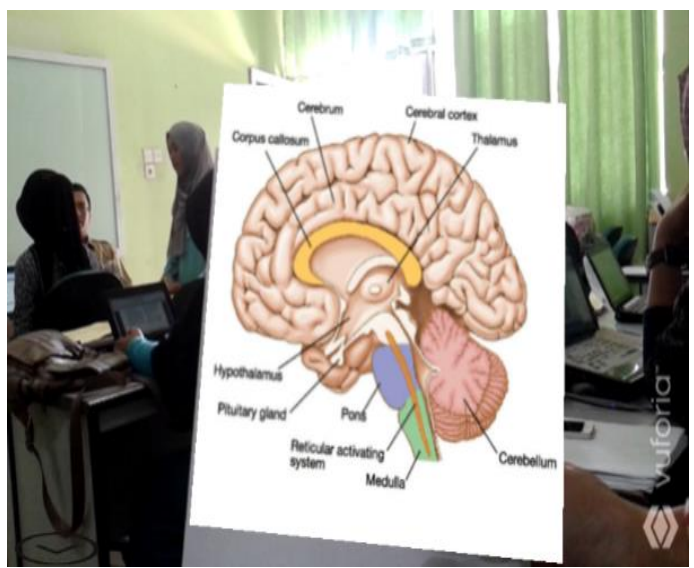

Gambar 14. Brain Anatomy AR Content Display

Gambar 14 merupakan konten organ otak yang ditampilkan. 


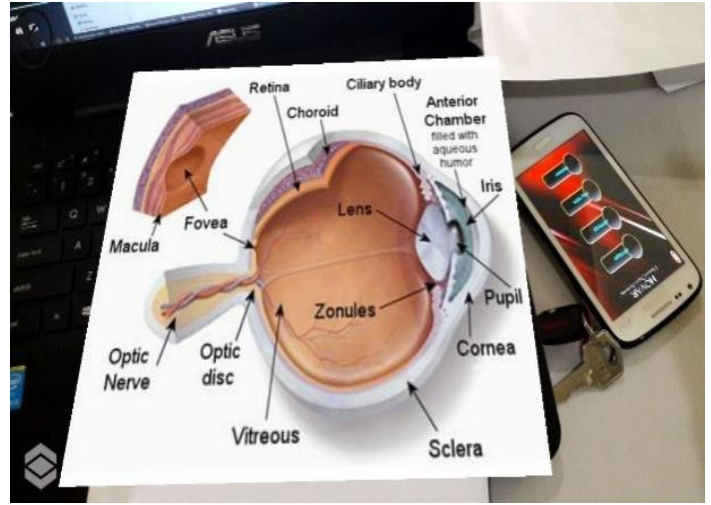

Gambar 15. Eye Anatomy AR Content Display

Gambar 15 merupakan tampilan konten anatomi mata setelah aplikasi berhasil mengenali marker mata.

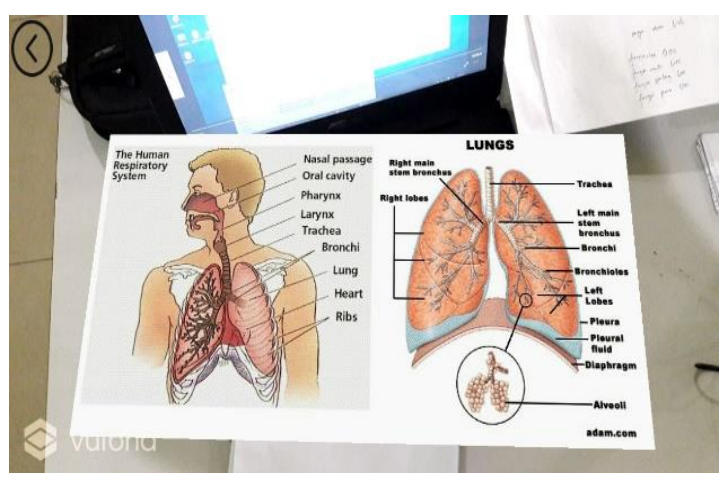

Gambar 16. Lung Anatomy AR Content Display

Gambar 16 merupakan tampilan konten anatomi paru-paru setelah aplikasi berhasil mengenali marker mata.

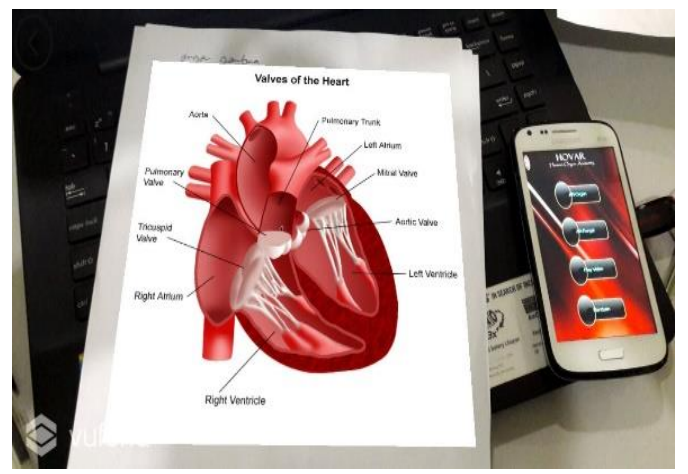

Gambar 17. Heart Anatomy AR Content Display
Gambar 17 merupakan tampilan konten anatomi jantung setelah aplikasi berhasil mengenali marker mata.

Menu AR Fungsi digunakan untuk menampilkan fungsi dan keterangan dari organ. Saat menu AR Fungsi diklik, fitur kamera akan diaktifkan. Kemudian user dapat menempatkan marker pada jangkauan kamera sama seperti saat melihat anatomi organ pada menu AR Organ.

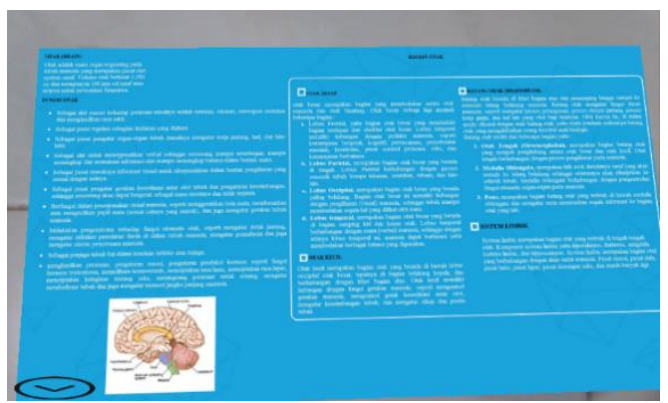

Gambar 18. Konten Fungsi dan Keterangan Organ Otak

Gambar 18 adalah tampilan konten fungsi dan keterangan organ otak. Pada tampilan ini dijelaskan tentang fungsi otak dan bagianbagiannya.

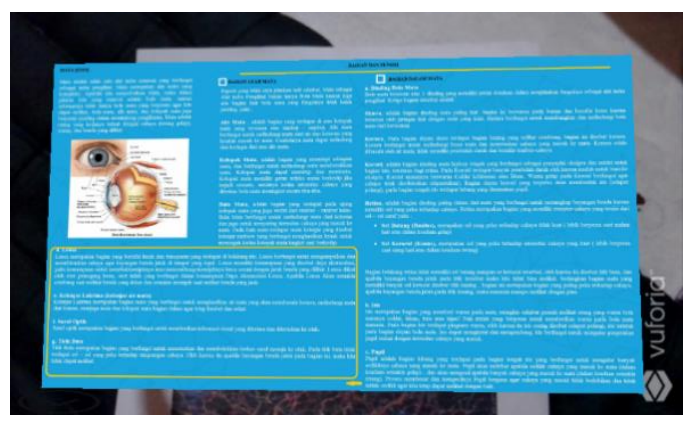

Gambar 19. Konten Fungsi dan Keterangan Organ Mata

Gambar 19 adalah tampilan konten fungsi dan keterangan organ mata. Pada tampilan ini dijelaskan apa itu mata serta bagian-bagian dan fungsinya. Pengguna secara fleksibel dapat menggerakkan kamera, untuk melihat tampilan yang lebih jelas user dapat mengarahkan kamera lebih dekat ke marker. 


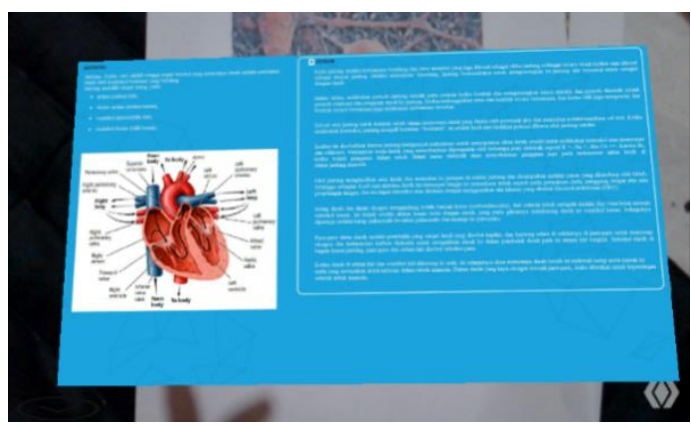

Gambar 20. Konten Fungsi dan Keterangan Organ Jantung

Gambar 20 adalah tampilan konten fungsi dan keterangan organ jantung. Tampilan ini menampilkan fungsi dari organ jantung.

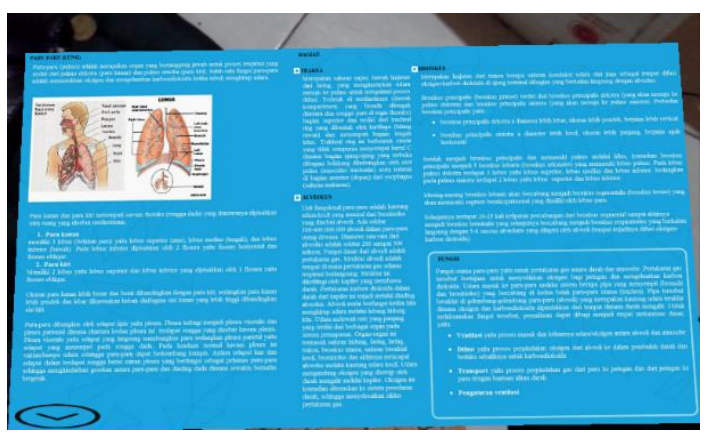

Gambar 21. Konten Fungsi dan Keterangan Organ Paru-Paru

Gambar 21 adalah tampilan konten fungsi dan keterangan organ paru-paru.

\section{Pengujian dengan Usability Test}

Pengujian dilakukan dengan menggunakan usability test. Usability test dilakukan dengan memberikan sejumlah pertanyaan (quesioner) kepada user/responden.

Dalam proses pengujian usability, peneliti menggunakan enam buah pertanyaan yaitu:

1. Apakah aplikasi mudah digunakan ?

2. Apakah informasi bisa dilihat dengan jelas?

3. Seberapa berguna aplikasi dalam menolong anda mempelajari informasi tentang organ tubuh manusia (terutama otak, mata, jantung dan paru-paru)?
4. Apakah informasi yang ditampilkan mudah untuk diingat?

5. Apakah anda menikmati saat menggunakan aplikasi?

6. Apakah anda tertarik menggunakan aplikasi ini kembali untuk belajar?

Setiap pertanyaan tersebut dijawab dengan Likert scale yaitu dengan memberikan poin nilai 1-7 (1 sampai 7), dimana skala 1 = sangat sulit / sangat tidak berguna / sangat tidak banyak / sangat tidak menikmati / sangat tidak tertarik dan skala $7=$ sangat mudah / sangat berguna / sangat banyak sangat menikmati / sangat tertarik.

Selain memberikan poin nilai responden juga diberikan kolom untuk memberikan alasan atau pendapatnya pada setiap pertanyaan.

Pada pengujian usability, peneliti melakukan pengujian kepada 9 (sembilan) responden dimana 8 (delapan) responden adalah perempuan dan 1 (satu) responden adalah laki-laki. Sebelum mengisi quesioneruser terlebih dahulu mencoba menggunakan aplikasi, umumnya selama 10 menit. Gambar 19 berikut adalah hasil dari quesioner yang diberikan pada responden. Pada gambar menunjukkan jumlah responden pada skala.

Berdasarkan hasil pengujian 93,65\% responden setuju bahwa aplikasi mudah digunakan. Responden memberikan alasan aplikasi mudah digunakan antara lain karena aplikasi sudah memiliki panduan dan dalam penggunaan aplikasi, responden hanya perlu meletakkan marker pada jangkauan kamera

Pada pertanyaan kedua 92,06\% responden setuju bahwa informasi yang ditampilkan pada aplikasi dapat dilihat dengan jelas. Beberapa responden memberikan pendapatnya bahwa aplikasi memberikan informasi dengan 
jelas karena anatomi organ tubuh ditampilkan dalam bentuk gambar.

Pada pertanyaan ketiga 90,48\% responden berpendapat bahwa aplikasi ini berguna bagi mereka untuk mempelajari informasi tentang organ.

Pada pertanyaan keempat $84,34 \%$ responden setuju bahwa informasi yang ditampilkan mudah untuk diingat. Hal tersebut dikarenakan informasi anatomi organ ditampilkan dalam bentuk gambar dengan bagian-bagiannya yang jelas.

Pada pertanyaan kelima $90,48 \%$ responden menyatakan bahwa mereka menikmati saat menggunakan aplikasi ini.

Dan pada pertanyaan keenam 93,65\% responden tertarik untuk menggunakan aplikasi ini untuk belajar.

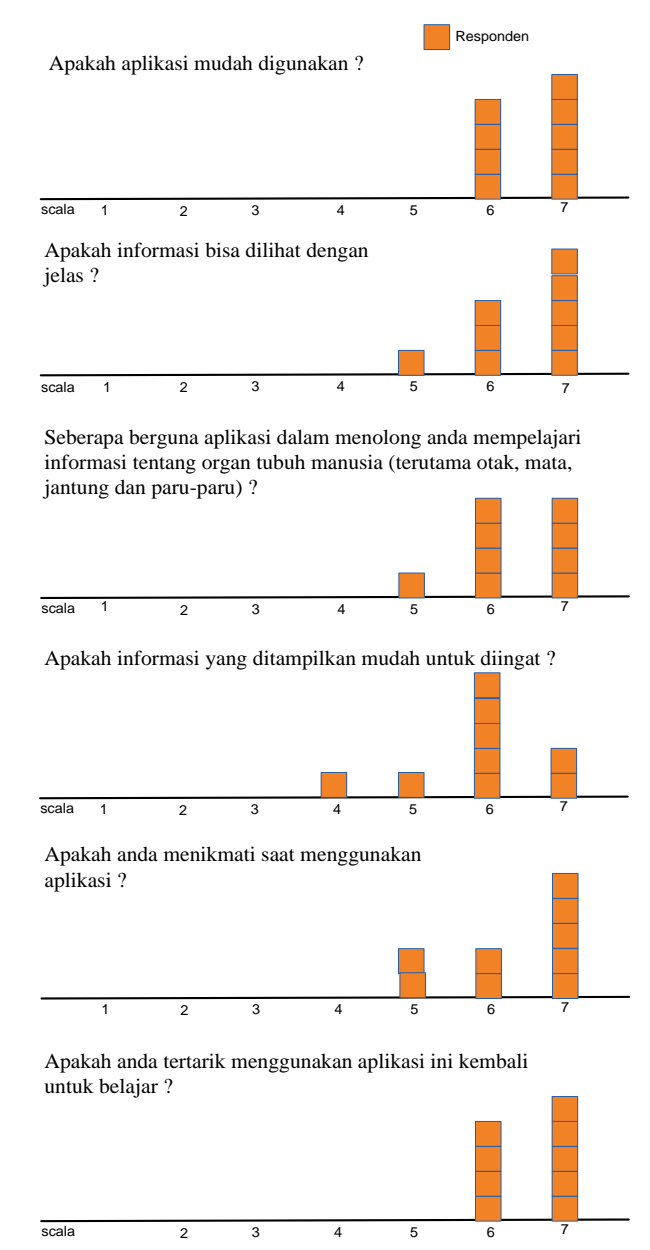

Gambar 22. Hasil Usability Quisioner dalam 7-point Likert Scale
Dari jumlah persentase setiap pertanyaan menunjukkan bahwa aplikasi Visualisasi Anatomi Organ Tubuh Manusia dengan Teknik Marker Based AR yang dibangun berhasil diterapkan. Aplikasi ini mudah digunakan dan dapat memberikan informasi tentang anatomi organ tubuh manusia dengan sangat jelas. Aplikasi ini juga sangat diminati karena memberikan pengalaman belajar yang berbeda dengan teknik Marker Based AR. Dan juga aplikasi ini dapat digunakan untuk belajar tentang anatomi organ tubuh manusia (khususnya otak, mata, jantung dan paru-paru).

\section{SIMPULAN}

Berdasarkan hasil implementasi dan pengujian aplikasi HOVAR (Human Organ Anatomy Visualized with Augmented Reality) yang menerapkan teknik Marker Based Augmented Reality pada penelitian ini, penulis dapat menyimpulkan bahwa:

1. Teknik Marker Based Augmented Reality berhasil diaplikasikan untuk membuat aplikasi visualisasi anatomi organ tubuh manusia pada perangkat smartphone platform Android. Teknik Marker Based AR berhasil diimplementasikan untuk menampilkan anatomi organ tubuh manusia sesuai dengan marker.

2. Aplikasi visualisasi anatomi organ tubuh manusia yang dibuat cukup menarik bagi pengguna. Berdasarkan pengujian aplikasi HOVAR, sebanyak 90,74\% responden setuju bahwa aplikasi ini mudah digunakan, informasi anatomi organ yang ditampilkan dapat dilihat dengan jelas, berguna bagi user untuk mempelajari informasi tentang organ, pengguna menikmati dan tertarik untuk 
menggunakan aplikasi ini untuk belajar.

\section{DAFTAR PUSTAKA}

Azuma, R. (1997). A Survey of Augmented Reality. Presence: Teleoperators and Virtual Environments, 6(4), 355-385

Brodkin, J. (2013). How Unity 3D Became a Game-Development Beast.

http://insights.dice.comdiakses pada 4 Oktober 2016

ISO/IEC. (1999). 13407 HumanCentered Design Processes for Interactive Systems. ISO/IEC 13407: 1999 (E)

Milgram, P., Takemura, H., Utsumi, A. \& Kishino, F. (1994). Augmented reality: A class of displays on the reality virtual continuum. SPIE Telemanipulator and Telepresence Technologies, 2351, 282-292

Nielsen, J. (2000). Usability Engineering. San Francisco USA: Morgan Kaufmann Publishers
Olwal, A. (2009). An Introduction to Augmented Reality. Adopted from Olwal, A. Unobtrusive Augmentation of Physical Environments: Interaction Techniques, Spatial Displays and Ubiquitous Sensing. Doctoral Thesis. KTH. Department of Numerical Analysis and Computer Science.Trita-CSC-A. ISSN 1653572

Raj, K., D’Souza, A., Shanbhag, C., \& D'Shouza, D. (2015). AR Application Using Android OS. International Journal of Innovative Research in Computer and Communication Engineering, 3(7), 126-129

Rekimoto, J., \& Ayatsuka, Y. (2000). Cybercode: Designing Augmented reality Environments with Visual Tags. Proceedings of Designing Augmented reality Environments 